\title{
Dynamic characteristics of Taiwanese traditional Dieh-Dou timber structures
}

\author{
S. Y. Yeo ${ }^{1}$, M. F. Hsu ${ }^{1}$, K. Komatsu ${ }^{2}$ \& W. S. Chang ${ }^{3}$ \\ ${ }^{1}$ Department of Architecture, National Cheng Kung University, \\ Taiwan, ROC \\ ${ }^{2}$ Laboratory of Structural Function, RISH, Kyoto University, Japan \\ ${ }^{3}$ Department of Architecture and Civil Engineering, \\ University of Bath, UK
}

\begin{abstract}
This study attempts to explore the structural behaviour of traditional Dieh-Dou timber structure under different combinations of bracket structural forms and roof dead loads. The parameters used include two different structural forms (symmetric and asymmetric) and three different levels of roof weight (1.7, 2.6 and 3.5 tons) which represent the span distance between two parallel frames at 3, 4.5 and 6 meters. Two different semi full-scale specimens, made of China Fir (Cunninghamia lanceolata), were mounted and tested on the shaking table of National Centre for Research on Earthquake Engineering (NCREE) in Taipei. Time-history record (TCU 084) from the 1999 Chi-Chi earthquake in Taiwan was used to test at a level of 20,42, 60, 80 and $100 \%$. System identifications were carried out between every test to monitor the integrity of the structures. Results showed that increase vertical loadings will have significant effect on the natural frequencies and global structural stiffness of the specimens. Next, the experimental results were mapped with the theoretical model for initial stiffness prediction, whereby the entire structural frame was assumed to be a lump mass system with Single-Degree-Of-Freedom (SDOF). The predicted stiffness model is generally in good agreement with the dynamic results of both structural forms. This study suggests that the effects of increasing vertical loadings should be taken into consideration during future evaluation process. Although using SDOF system to estimate the initial stiffness seems highly probable, more work still
\end{abstract}


needs to be undertaken on other types of theoretical models to find out the most optimal evaluation methods for Dieh-Dou timber frame.

Keywords: Dieh-dou timber structure, bracket system, shaking table experiment, natural frequency, initial stiffness prediction, hysteretic loops.

\section{Introduction}

Bracket system and heavy roof are unique characteristics of traditional oriental timber frame. During the 1999 Chi-Chi earthquake, many invaluable historic timber structures were destroyed in Taiwan. Since then, a series of research was initiated to investigate the structural performance of the Taiwanese traditional timber structures. Generally, two main types of traditional timber frames are found in Taiwan, namely the Chuan-Dou frame and Dieh-Dou frame. For the past decade, much emphasis had been placed on the Chuan-Dou type as they account for nearly half of the total count of damaged historic buildings during the Chi-Chi earthquake. Having completed the first half of the study, now the focus is shifted to the studies of Dieh-Dou frame. For years, the debate over various structural issues such as the effects of vertical loadings, adequacy of reinforcement for damaged parts and connections etc., particularly for this type of traditional timber frame, is still on-going as both conservation architects and engineers are unable to find an optimal gauge for the evaluation and maintenance of traditional timber frame. This is mainly due to the limited research [1-9] found so far on the structural performance of Dieh-Dou type timber frame. Moreover, most of these studies are static-based experiments, hence in this paper, the dynamic structural performance of the Dieh-Dou timber frame will be studied.

\section{Experiment}

The aim of this experiment is to understand the dynamic structural behaviour of traditional Dieh-Dou timber structure under different combination of structural forms and roof dead loads. Two different semi-full-scale structural forms (symmetric and asymmetric specimens, fig. 1), made of China Fir (Cunninghamia lanceolata), were mounted and tested on the shaking table of National Centre for Research on Earthquake Engineering (NCREE) in Taipei. Based on unidirectional excitation mode, the two specimens were subjected to three different levels of roof weights - 1.7, 2.6 and 3.5 ton - each representing the span interval between two parallel frames of 3, 4.5 and 6 meter respectively. Time-history record (TCU 084, fig. 2) from the 1999 Chi-Chi earthquake in Taiwan was used. Although the seismic record used has a Peak Ground Acceleration (PGA) of 989 gal, but in this dynamic test, the amplitude was downscale to $160,336,480,640$ and 800 gal, to represent the test levels of 20, 42, 60, 80 and 100\% respectively. System identifications were carried out between every test to monitor the integrity of the structures. The parameters used for this study are mainly roof weight, PGA and natural frequency. 


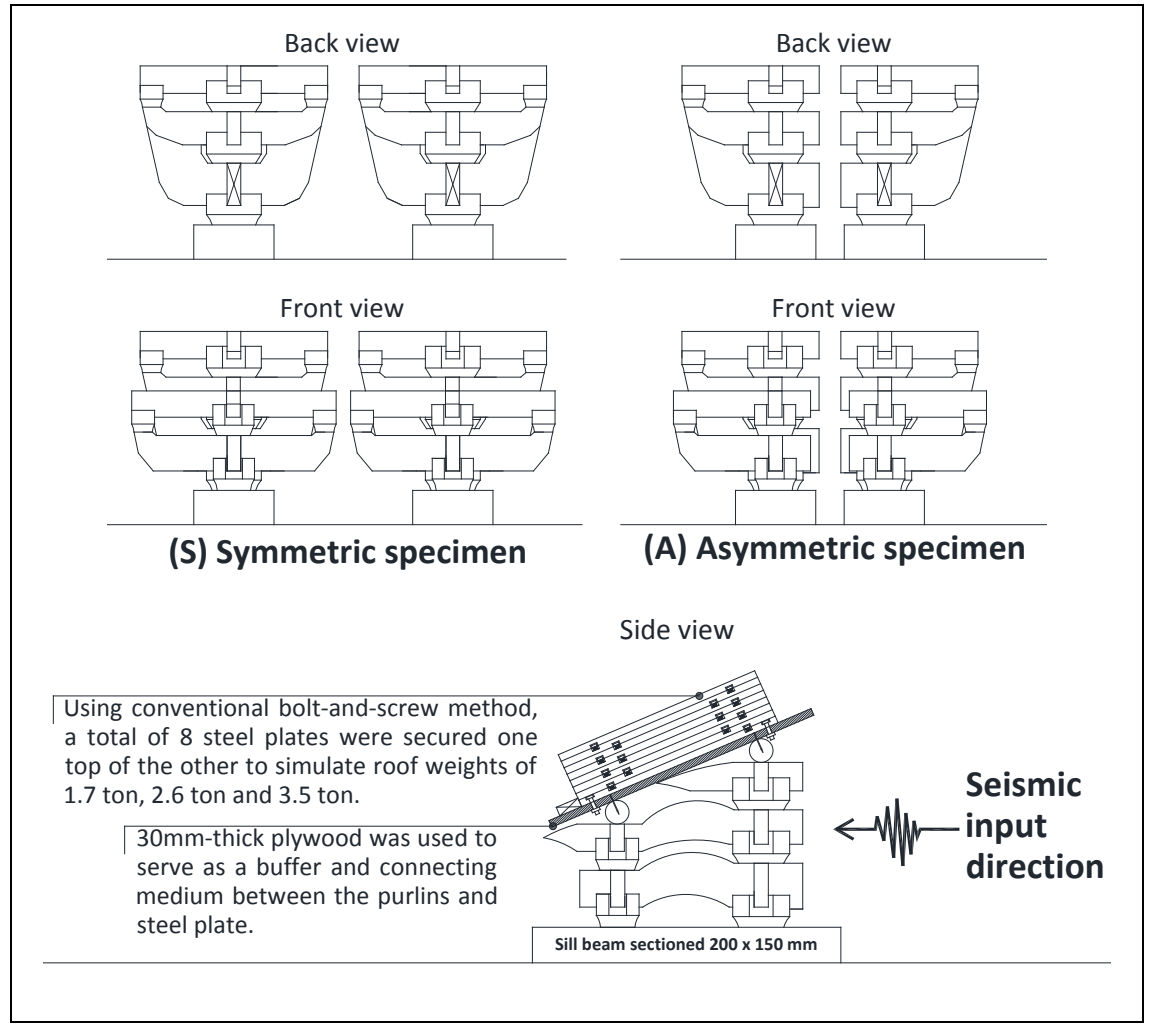

Figure 1: $\quad$ Overview of symmetric and asymmetric specimen setup.

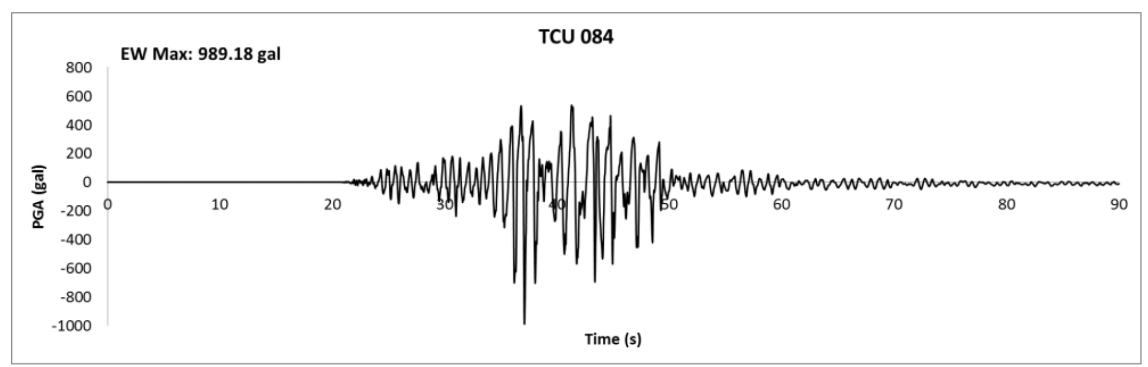

Figure 2: $\quad$ Original time history of TCU 084. 


\section{Results and discussion}

\subsection{Reduction of natural frequency with increasing roof weight and seismic input}

The natural frequency of the structure after every seismic test was generated using a Japanese spectra program (SPCANA ${ }^{\circledR}$ ver.4.91) via the Fast Fourier Transform (FFT) method. By using the theoretical free vibration theory, the natural frequency of the bracket system can be expressed as:

$$
f=\frac{1}{T}
$$

where $\mathrm{f}$ and $\mathrm{T}$ represent the natural frequency (cycles/sec $=\mathrm{Hz}$ ) and time (seconds) respectively.

The natural frequency from eqn. (1) reflects the global stiffness of the entire structure, in other words, the larger the $f$ value, the stiffer is the entire structure and vice versa. With reference to the past shaking table experiment done at Chubu University in Japan, where one old asymmetric specimen was subjected to a maximum limit of $15 \mathrm{kN}$ and 330 gal, the natural frequency of the specimen drop from $6.05 \mathrm{~Hz}$ to $4.12 \mathrm{~Hz}$ (fig. 3). The above observation is also seen in the symmetric and asymmetric structures. With reference to table 1 and fig. 4 , the natural frequencies of both types of structures generally decline under the effects of increasing roof loading and seismic loading input.

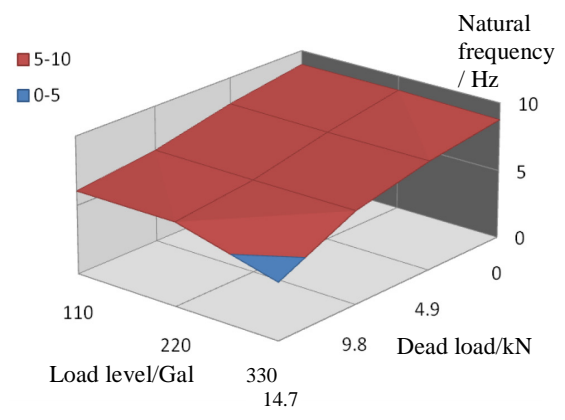

Figure 3: Effects of various load levels and dead loads on the natural frequencies of the asymmetric specimen.

Table 1: Effects of increase loading levels and dead loads on both types of structure.

\begin{tabular}{cccc}
\hline $\begin{array}{c}\text { Load Level } \\
(\% / \mathrm{Gal})\end{array}$ & $\begin{array}{c}\text { Dead Load } \\
(\mathrm{kN})\end{array}$ & $\begin{array}{c}\text { Symmetric } \\
(\mathrm{Hz})\end{array}$ & $\begin{array}{c}\text { Asymmetric } \\
(\mathrm{Hz})\end{array}$ \\
\hline $0 / 0$ & 17 & 4.55 & 4.55 \\
$20 / 160$ & 17 & 4.5 & 4.51 \\
$42 / 336$ & 17 & 4.49 & 4.56 \\
$60 / 480$ & 17 & 4.13 & 4.61 \\
\hline $0 / 0$ & 26 & 4.55 & 3.98 \\
$20 / 160$ & 26 & 3.92 & 3.94 \\
$42 / 336$ & 26 & 3.58 & 3.95 \\
$60 / 480$ & 26 & 3.58 & 3.92 \\
\hline $0 / 0$ & 35 & 3.39 & 3.36 \\
$20 / 160$ & 35 & 3.35 & 3.35 \\
$42 / 336$ & 35 & 3.3 & 3.39 \\
$60 / 480$ & 35 & 3.22 & 3.54 \\
\hline
\end{tabular}



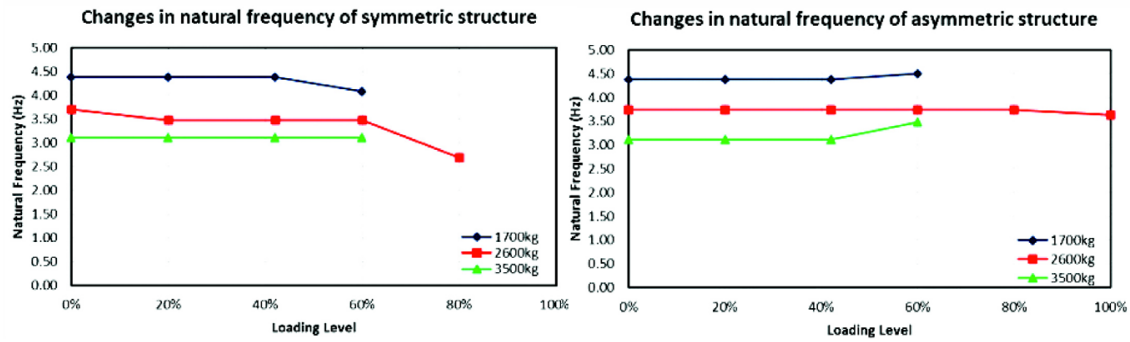

Figure 4: Changes in natural frequencies of both structural types with increasing load levels and dead loads.

\subsection{Initial stiffness prediction}

Using Chang's [8] proposal of setting the entire bracket set as a Single-degree-of freedom (SDOF) system, and assumed the weight of bracket set to be negligible, the steel plates (roof loads) become the main mass contributor to be responsible for the global structural stiffness. By applying the concept of simple harmonic motion and free vibration further, the natural frequency can be presented as:

$$
f=\frac{1}{T}=\frac{1}{2 \pi} \sqrt{\frac{k}{m}}
$$

After rearranging eqn. (2), the following theoretical global stiffness prediction, $k$ was obtained:

$$
k=\frac{4 \pi^{2} m}{T^{2}}
$$

When the estimated stiffness predictions were mapped onto the dynamic results of both symmetric (fig. 5) and asymmetric specimens (fig. 6), good initial stiffness prediction results were achieved. Thus implying the above theoretical stiffness prediction method could be considered as an alternative to predict the initial stiffness of the Dieh-Dou timber frame.

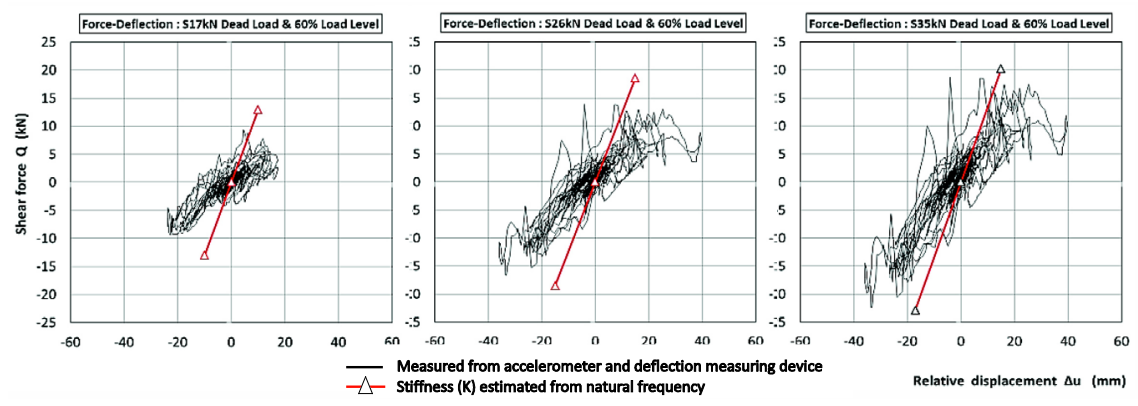

Figure 5: Comparison of estimated stiffness with experiment results for symmetric specimens under varying dead loads. 


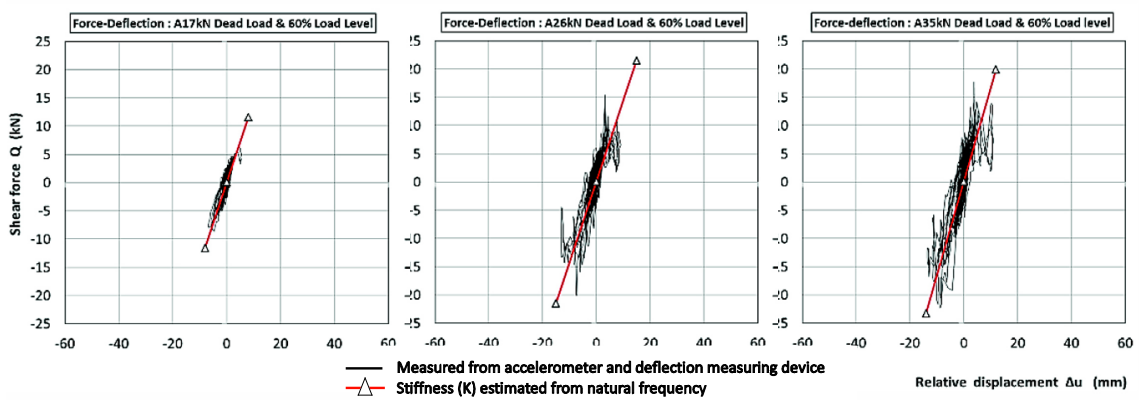

Figure 6: Comparison of estimated stiffness with experiment results for symmetric specimens under varying dead loads.

\subsection{Ultimate strength}

Under three different roof loads of 1.7 ton, 2.6 ton and 3.5 ton, each representing the inter-frame span distance of $3 \mathrm{~m}, 4.5 \mathrm{~m}$ and $6 \mathrm{~m}$ respectively, the declination trend of the above natural frequencies also implies an overall decrease in the global stiffness of various span distances. During the experiment, it was found that shear failure of both symmetric and asymmetric specimens begin from $336 \mathrm{gal} / 3.5$ ton (or $6 \mathrm{~m}$ span interval), as shown in table 2. Damage pattern of both specimens generally starts from the Dou member and eventually spread out to the mortise-tenon connections of adjoining members, as shown in figs 8 and 9 . The above results can be used as a guide for future structural evaluation of the entire system's seismic tolerance limit.

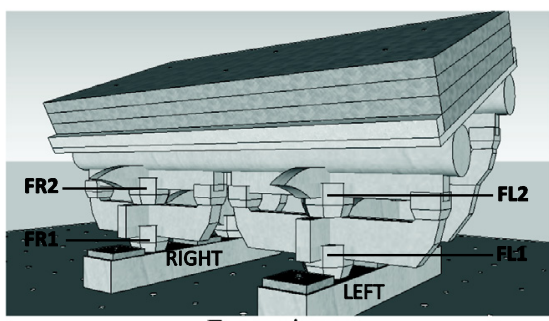

Front view

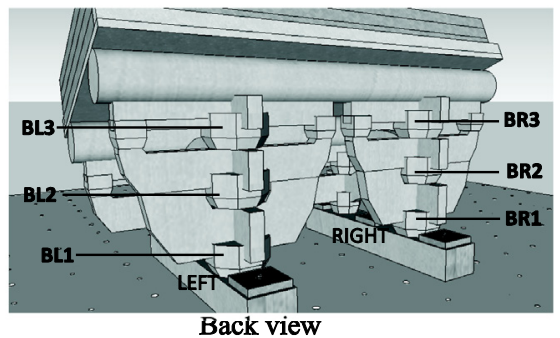

Back view

Figure 7: $\quad$ Numbering of the Dou member for Table 2's reference. 
Table 2: $\quad$ Damage pattern of the Dou member of both specimens.

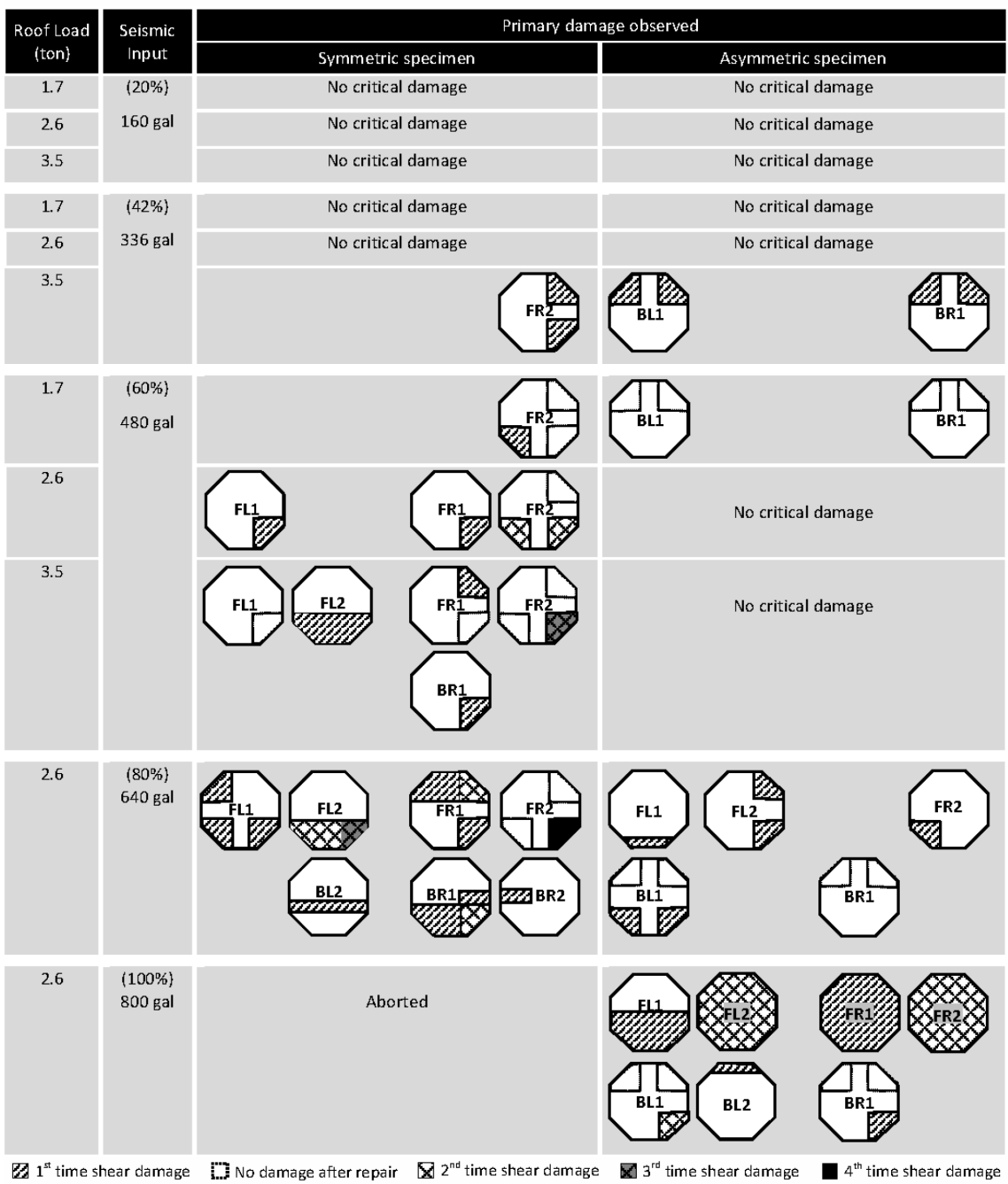



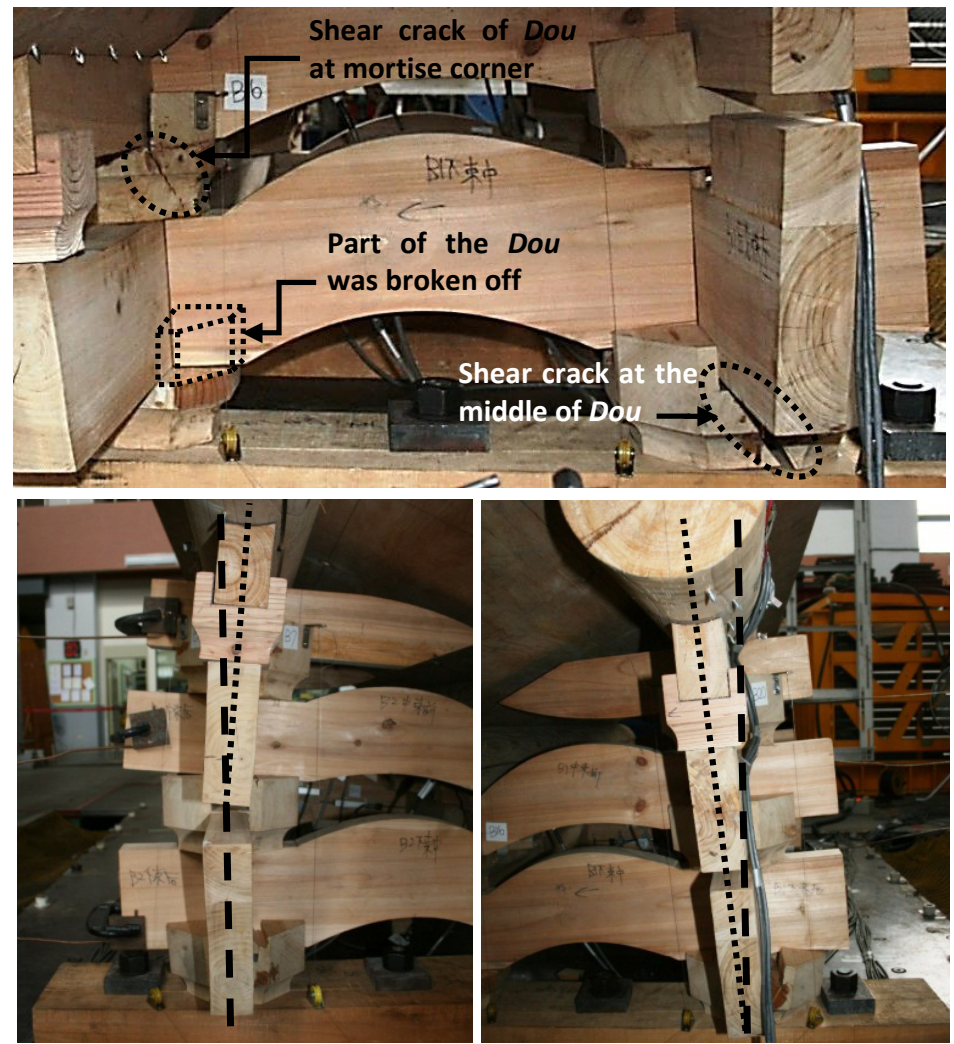

- - Original central alignment $\quad$-.. Misalignment caused by high seismic force

Slanting of the other adjoining members as a result of Dou deformation

Figure 8: $\quad$ General damage patterns observed in both specimens.

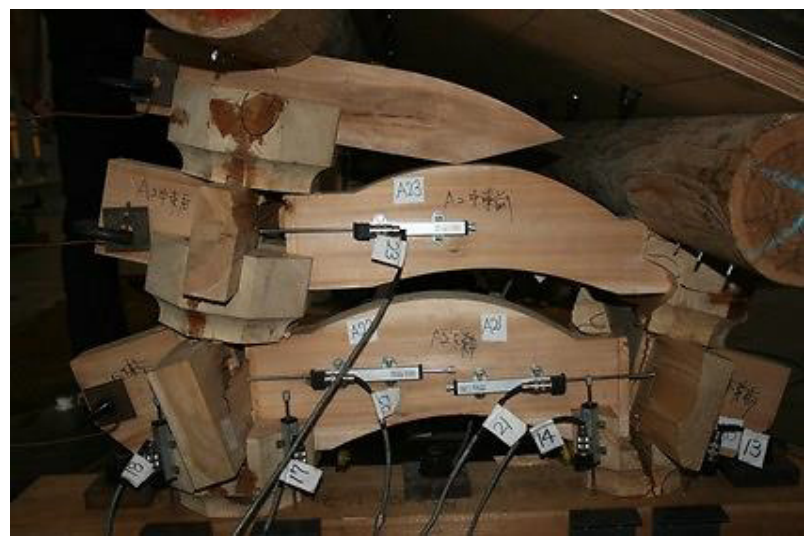

Figure 9: Final damage mode of asymmetric specimen under maximum 800 gal. 


\section{Conclusion}

The dynamic test has been carried out to investigate the structural behaviour of the Dieh-Dou frame and the following conclusion can be drawn:

(1) Varying vertical loads and loading levels have significant effect on the global structural stiffness of the specimen.

(2) Overall stiffness of both types of structural forms falls within $336 \mathrm{gal} / 35 \mathrm{kN}$ (or $6 \mathrm{~m}$ span interval), hence this reference can be viewed as the ultimate strength of Dieh-Dou structure.

(3) This study suggests that the effects of varying vertical loadings should be taken into consideration during future evaluation process.

(4) Although the use of SDOF system to estimate the initial stiffness seems highly promising, more testing still needs to be done on other types of theoretical models to find out the most optimal evaluation methods for Dieh-Dou timber frame.

\section{Acknowledgements}

This research is fully supported by the Taiwan National Science Council under the grant project number NSC-100-2221-E-006-225-. The semi full-scale experiments were performed at National Centre for Research on Earthquake Engineering (NCREE) in Taipei. Special thanks go to all members of NCREE and members of both Laboratories, namely the Min-Fu Hsu Lab of NCKU Architecture department and Laboratory of Structural Function, RISH, Kyoto University for making the experiments possible. Sincere gratitude is also extended to the Tan Kah Kee Foundation (Singapore) for awarding the Tan Ean Kiam Postgraduate Scholarship to the first author.

\section{References}

[1] Fujita, K., Sakamoto, I., Ohashi, Y. and Masahiko, K., Static and dynamic loading tests of bracket complexes used in traditional timber structures in Japan, Proc. of the $12^{\text {th }}$ World Conf. On Earthquake Engineering, Paper no. 0851, 2000.

[2] Fujita, K., Kimura, M., Ohashi, Y. and Sakamoto, I., Shaking table test of Kumimono used in traditional wooden architecture: Part 6 - Stiffness of Degumi bracket complex, Annual meeting of Architectural Institute of Japan, 2000. (In Japanese.)

[3] Fang, D.P., Iwasaki, S., Yu, M.H., Shen, Q.P., Miyamoto, Y. and Hikosaka, H., Ancient Chinese timber architecture, I: experimental study, Journal of structural engineering, 127(11), pp. 1348-1357, 2001.

[4] Fang, D.P., Iwasaki, S., Yu, M.H., Shen, Q.P., Miyamoto, Y. and Hikosaka, H., Ancient Chinese timber architecture, II: dynamic characteristics, Journal of structural engineering, 127(11), pp. 1358-1364, 2001. 
[5] Tsai, P-H and D'Ayala, D., Seismic vulnerability of historic DiehDou timber structures in Taiwan, Engineering structures, 30(8), pp. 21012113, 2008.

[6] Fang, D.P., Iwasaki S., Yu M.H., Shen Q.P., Miyamoto Y. and Hikosaka H., Performance-based seismic assessment method for Taiwanese historic DiehDou timber structures, Earthquake engineering and structural dynamics, 40(7), pp. 709-729, 2011.

[7] Yeo, S. Y., Chang, W-S, Hsu, M-F, Komatsu, K., The structural behaviour of timber frame under various roof weights - using Taiwanese traditional Die-Dou timber frame as case study, East Asian Architectural Culture International Conference (EAAC), 2011.

[8] Chang, W-S et al., Dynamic properties of a traditional complex bracket sets in an oriental temple, Proc. of the $12^{\text {th }}$ World Conf. On Timber Engineering, 2012.

[9] Yeo, S. Y., Komatsu, K., Hsu, M-F and Chang, W-S, A preliminary study on the structural stiffness of Taiwanese traditional Dieh-Dou asymmetric timber frame, Proc. of the 63th Annual Meeting of Japan Wood Research Society, 2013. 